Journal of Korean Powder Metallurgy Institute

Vol. 18, No. 2, 2011

DOI: $10.4150 /$ KPMI.2011.18.2.176

\title{
Influence of Processing Conditions on PVDF Properties
}

\author{
S. M. Lebedev*, O. S. Gefle and M. V. Semenikhin \\ High-Voltage Research Institute of National Research Tomsk Polytechnic University \\ 2 A Lenin Avenue, 634028, Tomsk, Russia \\ (Received February 16, 2011; Revised March 25, 2011; Accepted April 11, 2011)
}

\begin{abstract}
Study of the main properties of PVDF films produced by two processing technologies such as hot pressing from a melt or solution casting was the aim of this paper. All samples were prepared of as-received PVDF powder. First group of samples was prepared by the hot pressing. Second group of samples was prepared by the solution casting method. PVDF powder was dissolved in dimethylformamide. To characterize properties of samples, different experimental methods such as FRA (dielectric spectroscopy), IR-spectroscopy and DSC/TGA analysis were used in this work. It was found that IR-spectra of both studied groups do not change compared to that for virgin PVDF powder. It confirms that molecular structure is practically independent on the processing technology of samples. The only difference has been found that new band centered at $1723 \mathrm{~cm}^{-1}$ appears for samples prepared by the hot pressing method. This absorption band is related with formation of $\mathrm{C}=\mathrm{C}$ bonds in samples prepared by the hot pressing method in contrast both to PVDF powder and samples prepared by the solution casting method.
\end{abstract}

Keywords : PVDF, Electrical, Thermal and molecular properties

\section{Introduction}

It is a well-known fact that change of conditions of preparation and processing of samples produced of PVDF( polyvinylidene fluoride) leads to the significant changes of their morphology [1-7]. Depending on these conditions three possible conformations of PVDF can be observed such as $\alpha-, \beta$-, and $\gamma$ phases $[7,8]$. In general, the g-form can be obtained by crystallizing PVDF from the melt [9]. The $\alpha$ form can be obtained by drawing and poling the PVDF film or by quenching the film from the molten state. The $\beta$-form can be prepared by annealing the film at a relatively high temperature [9]. The $\gamma$ and $\gamma$-forms of PVDF exhibit piezoelectricity, but not the $\alpha$-form [10].

The author has reported that two types of spherulites are observed in PVDF samples crystallized from the melt at any temperatures: the first type consists of large closelypacked spherulites of $\alpha$-phase possessing birefringence; and the second one consists of the mixed shape of $\alpha$ - and $\gamma$-phases with rare inclusions of a birefringent $\alpha$-phase[1]. Latest form is observed only at high crystallization temperatures.

The authors have found that when PVDF is crystallized at temperatures above $155^{\circ} \mathrm{C}$ it presents a multiform morphology composed of ringed, nonringed and mixed spherulites [3]. IR-spectroscopy showed that ringed spherulites are formed exclusively by the $\alpha$-phase when crystallization takes place at temperatures below $155^{\circ} \mathrm{C}$. Higher temperatures induce a solid-state $\alpha-\gamma$-phase transformation in these structures, increasing the amount of $\gamma$-phase with crystallization time. The non-ringed spherulites, only formed at crystallization temperatures above $155^{\circ} \mathrm{C}$, consist predominantly of the $\gamma$-phase, crystallized from the melt, with small $\alpha$-phase inclusions.

It has been shown that samples containing the three crystalline phases of PVDF: $\alpha, \beta$, and $\gamma$ have been obtained under distinct crystallization condi-

*Corresponding Author : [E-mail : serguei_lebedev@hotmail.com] 
tions. Samples containing exclusively non-oriented $\beta$ phase have been obtained by crystallization from dimethylformamide solution at $60^{\circ} \mathrm{C}$ [8]. Oriented $\beta$ phase has been obtained by uniaxial stretching at $80^{\circ} \mathrm{C}$ of an originally $\alpha$-phase sample. Samples containing exclusively $\beta$-phase have been obtained by melting and posterior cooling at room temperature. Samples containing both $\alpha$ - and $\gamma$-phases have been obtained by melt crystallization at $165^{\circ} \mathrm{C}$.

The authors have investigated the solubility of PVDF in various organic solvents and crystal structures of the PVDF bulk films cast from the solvents [11]. The films prepared from the polar solvents such as dimethylformamide (DMF), dimethyl sulfoxide (DMSO) dominantly showed $\gamma$-type crystals regardless of preparation temperature, while the films from tetrahydrofuran (THF) exhibit $\alpha$-type crystals and the ones from acetone and methyl ethyl ketone (MEK) show the characteristics of both $\alpha$ and $\gamma$-PVDF.

Evaluating influence of processing conditions on main properties of PVDF was the aim of this work. Electrical, thermal and molecular properties of PVDF samples prepared by both hot pressing from the melt and solution casting were studied by means of different experimental methods.

\section{Experimental Procedure and Samples}

Measurements of the real part $\varepsilon^{\prime}$ of the complex permittivity and loss factor $\tan \delta$ were carried out under $\mathrm{AC}$ voltage $3 \mathrm{~V}$ in the frequency range from $10^{-2} \mathrm{~Hz}$ to $1 \mathrm{MHz}$ by using the Solartron Instrument (Impedance/Gain-Phase Analyzer Solartron $1260+$ Dielectric Interface Solartron 1296) [12]. From five to ten measurements per decade over the frequency range were carried out for all samples.

Temperatures and temperature intervals of melting and decomposition of CPM', the heat flow and a weight loss of samples were measured in the temperature range from 25 to $500^{\circ} \mathrm{C}$ at a heating rate of $3^{\circ} \mathrm{C} / \mathrm{min}$ in an argon atmosphere by means of a combined DSC-DTA-TGA analyzer Q600 “A Instruments" From three to five samples of each composite were tested for all test conditions.

FTIR analysis was carried out by means of IRspectrometer Nicolet 5700 at the wavenumber range from 4000 to $400 \mathrm{~cm}^{-1}$.

As-received PVDF powder ("luoropolymer"Ltd., St-Petersburg, Russia) with particles size from 20 to $200 \mu \mathrm{m}$ was used as a polymeric material for samples in this study.

Films were produced by means of four different processing techniques: the hot pressing method, the solution casting method, and two compositions of them (Table 1). In the first case films were prepared in special compression molds from a PVDF melt. Compression molds filled with PVDF powder were placed into a vacuum oven heated up to $190^{\circ} \mathrm{C}$ for $3 \mathrm{~h}$. After that, compression molds were pressed in a hydraulic press at $12 \mathrm{MPa}$ for $20 \mathrm{~min}$. Samples studied were prepared as discs $75 \mathrm{~mm}$ in diameter and thicknesses of 20-150 $\mu \mathrm{m}$. Molds were slowly cooled up to ambient temperature under pressure in air. In the second case films were prepared from $10 \%$ solution of PVDF powder in dimethylformamide (DMF). Crystallization of films was carried out under isothermal conditions at $110^{\circ} \mathrm{C}$ in the vacuum oven. The third group of films has been produced by dissolution in DMF of a film prepared by the hot pressing method. The fourth group represented a film prepared by the hot pressing method from film prepared by the solution casting.

All samples were prepared as discs $75-100 \mathrm{~mm}$ in diameter and thicknesses of 20-150 $\mu \mathrm{m}$.

Table 1. Film processing conditions

\begin{tabular}{cl}
\hline \hline Type of film & \multicolumn{1}{c}{ Processing conditions } \\
\hline I & Solution casting \\
II & Hot pressing \\
III & Solution casting (from film of type II) \\
IV & Hot pressing (from film of type I) \\
\hline
\end{tabular}




\section{EXperimental Results and Discussion}

The results of dielectric spectroscopy for films prepared by the solution casting and the hot pressing methods are represented in Fig. 1 and 2. It can be seen that the dielectric relaxation spectra for two types of PVDF films do not differ from each other the only difference being that the frequency corresponding to the $\tan \delta_{\text {max }}$ position shifts towards to the higher frequency range for samples of type II compared to that for the samples of type I.

It is a well-known fact that all three crystalline phases of

PVDF possess the characteristic bands such as [13-14]:

- 531, 612, 766, 795, 855 and $976 \mathrm{~cm}^{-1}$-for $\alpha$-phase;

- 470, 511, 600, 745 and $840 \mathrm{~cm}^{-1}$ - for $\alpha$-phase;

- the band at $430 \mathrm{~cm}^{-1}$ for $\gamma$-phase; and

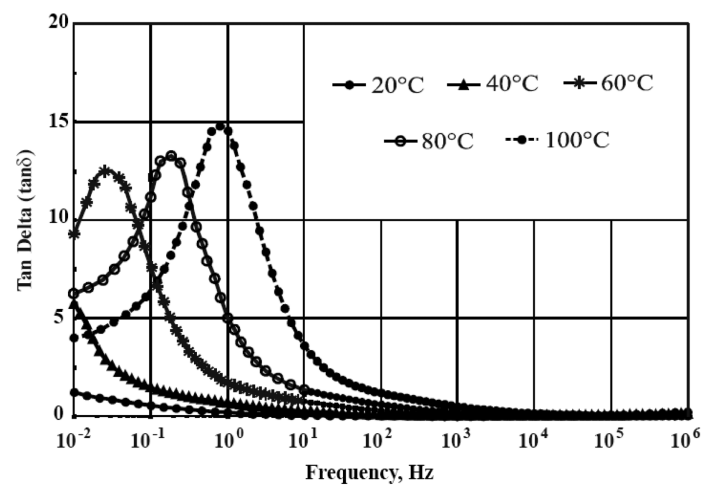

Fig. 1. Temperature-frequency dependencies of $\tan \delta$ for PVDF films prepared by the solution casting.

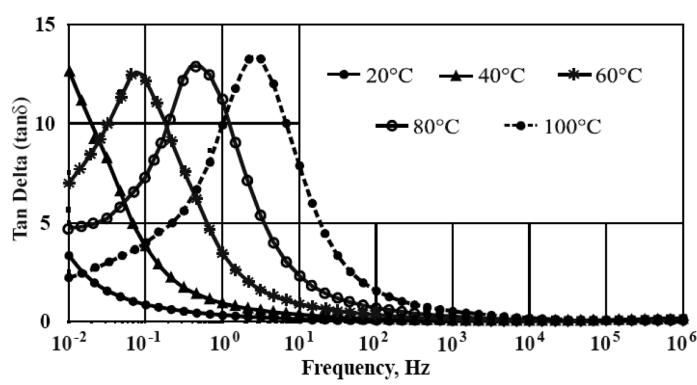

Fig. 2. Temperature-frequency dependencies of $\tan \delta$ for PVDF films prepared by the hot pressing from the melt.

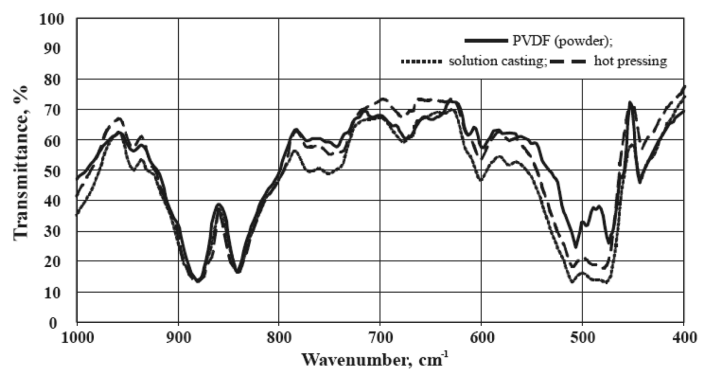

Fig. 3. FTIR spectra for both types of films and as-received PVDF.

- the band at $677 \mathrm{~cm}^{-1}$ characterizes defect bonds head-to-head or tail-to-tail [14].

An analysis of molecular structure of both types of $30-\mu \mathrm{m}$ films and as-received PVDF powder was performed by means of FTIR-spectroscopy. FTIR spectra of PVDF powder were measured by means of a special diffusion reflection gadget of the analyzer Q600. Experimental results of this study are presented in Fig. 3.

It can be seen that FTIR spectra of three sample types include all characteristic bands mentioned above. That is, all three crystalline phases $(\alpha, \beta$, and $\gamma)$ are observed both for film samples and asreceived PVDF powder. This fact testifies that the change of the processing conditions does not practically result in the modification of the molecular structure of PVDF. Furthermore, molecular structure of PVDF does not change even after secondary reprocessing of films.

One more interesting experimental fact was found when studying FTIR spectra. It has been found that processing of PVDF by the hot pressing method results in the appearance of a new band at $1723 \mathrm{~cm}^{-1}$ that characterizes presence of double $\mathrm{C}=\mathrm{C}$ bonds [15] in polymer (Fig. 4). This band is the result of overlapping of two bands connected with oscillations both of insolated $\left(1754 \mathrm{~cm}^{-1}\right)$ and conjugated $\left(1718 \mathrm{~cm}^{-1}\right) \mathrm{C}=\mathrm{C}$ bonds.

Fig. 4 shows that the intensity of the band at 1723 $\mathrm{cm}^{-1}$ is increased in the row: type III, type II, and type IV. It is obvious that this band is practically 


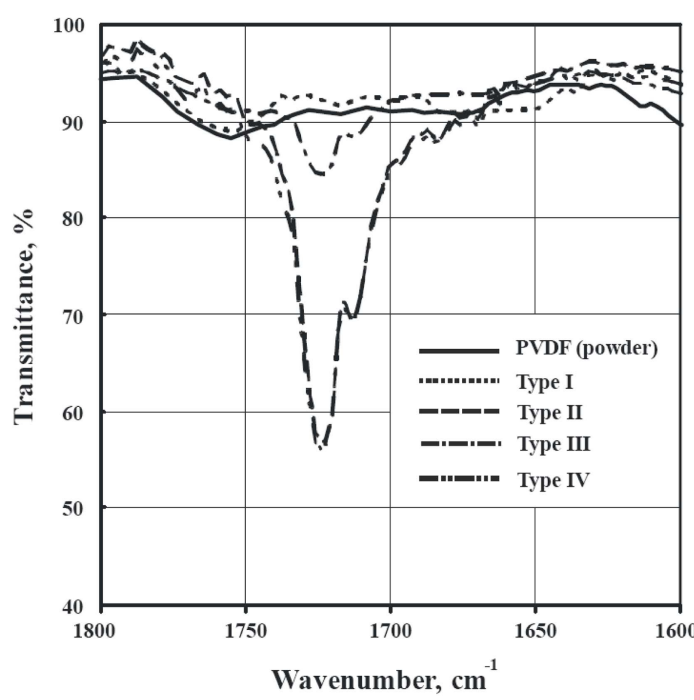

Fig. 4. FTIR spectra for PVDF powder and films.

absent both for as-received PVDF powder and film of type I.

That is, the appearance of this band is related with the processing technology, namely, with the formation of defect $\mathrm{C}=\mathrm{C}$ bonds in a polymer under the high temperature during the hot pressing from a melt. This supposition is confirmed by that the intensity of this band in films prepared by the solution casting method (type III) from the melt-solidified films is lower compared with a film of types II and IV. One can suppose that the more homogeneous molecular and sub-molecular structures should be formed in PVDF films prepared by the solution casting technology.

To verify this supposition, the study of thermal properties of PVDF films prepared by solution casting and hot pressing from the melt was performed. The results of thermal analysis of films are shown in Fig. 5 and 6, respectively. It can be seen that two endothermic minima are observed for both films. The first of them is related with the melting process and the second one with the decomposition process of PVDF.

The beginning melting temperature $\left(T_{b m}\right)$, the melt temperature $\left(T_{m}\right)$, the beginning decomposition tem-

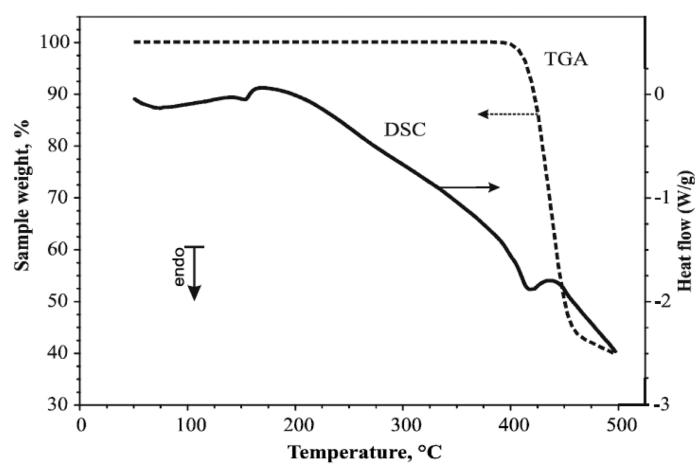

Fig. 5. DSC/TGA results for PVDF films prepared by the solution casting method (type I).

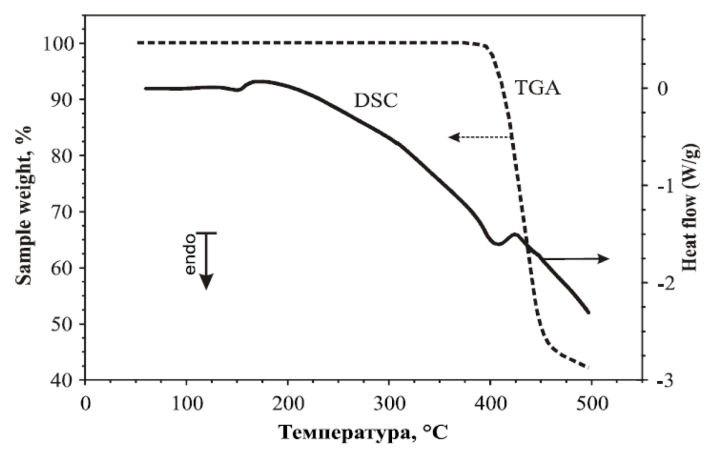

Fig. 6. DSC/TGA results for PVDF films prepared by the hot pressing method from the melt (type I).

Table 2. Thermodynamic properties of PVDF films

\begin{tabular}{ccccc}
\hline $\begin{array}{c}\text { Type of } \\
\text { film }\end{array}$ & $T_{b m},{ }^{\circ} \mathrm{C}$ & $T_{m},{ }^{\circ} \mathrm{C}$ & $T_{b d},{ }^{\circ} \mathrm{C}$ & $T_{d},{ }^{\circ} \mathrm{C}$ \\
\hline I & 140 & 154 & 400 & 415 \\
II & 132 & 152 & 390 & 403 \\
III & 136 & 152 & 397 & 411 \\
IV & 134 & 152 & 391 & 404 \\
\hline
\end{tabular}

perature $\left(T_{b d}\right)$, and the decomposition temperature $\left(T_{d}\right)$ for all PVDF films are listed in Table 2.

It is obvious that the film prepared by the solution casting (type I) possesses by the best thermodynamic properties compared to other films. It can be seen that the increase in the phase transition temperatures for this film is from 2 to $12^{\circ} \mathrm{C}$, while the film prepared by the hot pressing method (type II) has minimum thermal properties. It can be conditioned by formation of defect $\mathrm{C}=\mathrm{C}$ bonds resulting in the 
decrease of thermal properties of these films.

\section{Conclusions}

The main conclusions of this work are as follows.

1. It has been found that the dielectric relaxation spectra for two types of PVDF films prepared by the solution casting and the hot pressing do not differ from each other.

2. All three crystalline phases $(\alpha, \beta$, and $\gamma$ ) are observed both for films of types I and II and asreceived PVDF powder. This fact testifies that the change of the processing conditions does not practically result in the modification of the molecular structure of the PVDF films.

3. It has been found that processing PVDF by the hot pressing method results in the appearance of a new band at $1723 \mathrm{~cm}^{-1}$ that characterizes presence of double $\mathrm{C}=\mathrm{C}$ bonds in the PVDF film. This band is practically absent both for asreceived PVDF powder and film of type I.

4. The PVDF film prepared by the solution casting (type I) possesses by the higher thermodynamic properties compared to other films.

\section{Acknowledgement}

This work was supported by the Russian Special Federal Program "Scientific and Scientific-pedagogic staff of innovative Russia, 2009-2013" under contracts No. P407 and P1913.

\section{References}

[1] A. J. Lowinger: J. Polym. Sci.: Polym. Phys., 18 (2003) 793.

[2] M. Benz, W. B. Euler and O. J. Gregory: Langmuir, 17 (2000) 239.

[3] R. Gregorio Jr. and R. C. Capitao: J. Mater. Sci., 35 (2000) 299.

[4] R. Imamura, A. B. Silva and R. Gregorio Jr.: J. Appl. Polym. Sci., 110 (2008) 3242.

[5] C. J. L. Constantino, A. E. Job and R. D. Simoes: Appl. Spectroscopy, 59 (2005) 275.

[6] V. Sencadas, V. M. Moreira, S. Lanceros-Mendez, A S. Pouzada and R., Gregorio Jr.: Mater. Sci. Forum, 514/516 (2006) 872.

[7] J. S. Nunes, V. Sencades, A. Wu, A. L. Kholkin, P. M. Vilarinho and S. Lanceros-Mendez: Mater. Sci. Forum, 514/516 (2006) 915.

[8] R. Gregorio Jr.: J. Appl. Polym. Sci., 100 (2006) 3272.

[9] A. Takeno, N. Okui, T. Kitoh, M. Muraoka, S. Umemoto and T. Sakai: Thin Solid Films, 202 (1991) 213.

[10] H. Kawai: J. Appl. Phys., 8 (1969) 975.

[11] Y. J. Park, Y. S. Kang and C. Park: European Polymer Journal, 41 (2005) 1002

[12] Impedance/Gain-Phase Analyzer 1260 and Dielectric Interface 1296, User guide, (2001).

[13] V. Sencadas, C. M. Costa, V. Moreira, J. Monteiro, S. K. Mendiratta, J. F. Mano and S. Lanceros-Mendez: ePolymers, 2 (2005) 1.

[14] J. W. Kim, W. J. Cho and C. S. Ha: J. Polymer Sci. B: Polymer Phys., 40 (2002) 19.

[15] B. Hilczer, H. Smogor and J. Goslar: J. Mater. Sci., 41 (2006) 117. 